\title{
DYKE-DAVIDOFF-MASSON SYNDROME: AN UNCOMMON CAUSE OF REFRACTORY EPILEPSY
}

\author{
MOHAMMAD HANIF ${ }^{1}$, KAZI GIASUDDIN AHMED ${ }^{2}$, DEVENDRA NATH SARKAR ${ }^{3}$, MD.ISMAIL HOSSAIN ${ }^{4}$, \\ ROBED AMIN ${ }^{5}$
}

\begin{abstract}
A rare syndrome, Dyke-Davidoff-Masson Syndrome (DDMS), with a diagnostic conundrum, and the way it was solved is presented. DDMS is one among the syndromes associated with refractory epilepsy. We have come across a case of Dyke-Davidoff-Masson syndrome while investigating a case of refractory epilepsy. When cerebral hemi atrophy is associated with the radiological features of osseous hypertrophy of calvarium, hyper-pneumatisation of sinuses dilatation, DDMS is to be considered.
\end{abstract}

Key words: Dyke-Davidoff-Masson syndrome, Refractory epilepsy, cerebral hemi-atrophy.

\section{Introduction}

The Dyke-Davidoff-Masson Syndrome (DDMS) was first described by Dyke, Davidoff and Masson in $1933^{1}$. The study conducted by Albert Zilkha consisting of 5,000 CT studies of the head over a 2-year period found 10 patients with cerebral hemiatrophy ${ }^{2}$. Unal et al. reported male sex dominance in their study which was the largest series of DDMS in the literature ${ }^{3}$. DDMS is characterized by cerebral hemiatrophy with homolateral hypertrophy of the skull and sinuses and elevation of the sphenoid wing and petrous ridge, in association with contralateral hemiplegia, seizures, mental retardation. These findings are due to cerebral injury that may occur early in life or in utero. Thus etiology of DDMS may be classified as congenital or acquired(1). In the congenital type, there is usually no apparent etiologic factor and the symptoms are present at birth or shortly thereafter. In this category, the cerebral damage most likely occurs during intrauterine life which might be due to intrauterine vascular occlusion. In the acquired type, the symptoms are related to central nervous system damage that occurs in the perinatal period or later. Among the etiologic factors are trauma, infection, vascular abnormality, and ischemic and hemorrhagic conditions ${ }^{1,4,5,6,7}$, coarctation of the midaortic arch, subependymal germinal matrix, amniotic bands and intraventricular hemorrhage of premature infants ${ }^{2,6,8}$. We report a case of DDMS in an 20 years old girl who presented with right sided focal seizures, hemiparesis of the same side, and delayed milestones.

\section{Case Report}

A 20 years old female, hailing from Barisal, was admitted in to Rangpur Medical College Hospital, Rangpur through outdoor department with the complains of weakness of the left side of the body and recurrent convulsion since childhood. According to the statement of the patient's mother, she was the first issue. During pregnancy, she didn't receive antenatal care. She suffered from prolonged labour and home delivery was done. The first one and half years of the life of the patient was uneventful. Her mother couldn't mention about the delay of the milestones of development. But she told that her child first developed convulsion at about one and half years of age. The seizure lasts about five minutes and was associated with loss of consciousness and urinary incontinence. It involved all four limbs and movement was jerky in nature. The second attack occurred after one month. Then she suffered from recurrent seizures every two to three months. Gradually she developed weakness of left upper and lower limbs and her left upper limb become deformed. Progressively she became mentally retarded. She was sent to school but her school performance was below average. So she didn't attend school after class two. The patient had no history of head injury, trauma or accident.

1. Associate Professor, Department of Medicine, Mymensingh Medical College, Mymensingh.

2. Assistant Professor, Department of Neurology, National Institute of Neuroscience \& Hospital, Dhaka

3. Associate Professor, Department of Medicine, Rangpur Medical College, Rangpur.

4. Registrar, Department of Medicine, Rangpur Medical College \& Hospital, Rangpur.

5. Associate Professor, Department of Medicine, Dhaka Medical College, Dhaka.

Correspondence to: Dr.Md.Ismail Hossain, Registrar, Department of Medicine, Rangpur Medical College \& Hospital, Rangpur, Bangladesh. email-drrussel27@gmail.com.

Bangladesh J Medicine 2014; 25 : 31-34 


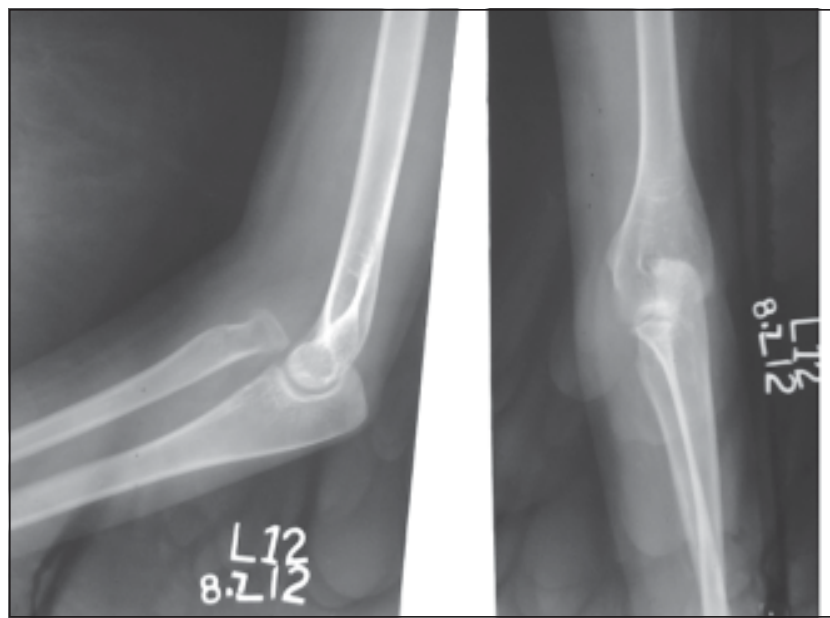

Fig-1(a)

On examination, the patient was ill looking, mildly anaemic, anicteric, not cyanosed, no lymphadenopathy, pulse rate 92/min, BP 100/60 $\mathrm{mm}$ of $\mathrm{Hg}$. On neurologic examination, higher psychic function was intact, GCS 15, cranial nerves intact, sensory function intact, reflexes were exaggerated in left upper and lower limbs, clonus absent, planter response extensor in left side, muscle power $3 / 5$ on left side and $5 / 5$ on right side tone normal.

Her investigation showed $\mathrm{Hb}-60 \%$, ESR-25 $\mathrm{mm}$ in $1^{\text {st }}$ hour,TC-9000/cmm, neutrophil-60\%, lymphocyte$30 \%$, Monocyte-5\%, Basophil-3\%, Esonophil-2\%.RBS$5.3 \mathrm{mmol} / 1$, serum creatinine $0.6 \mathrm{mg} / \mathrm{dl}$. X-ray of left

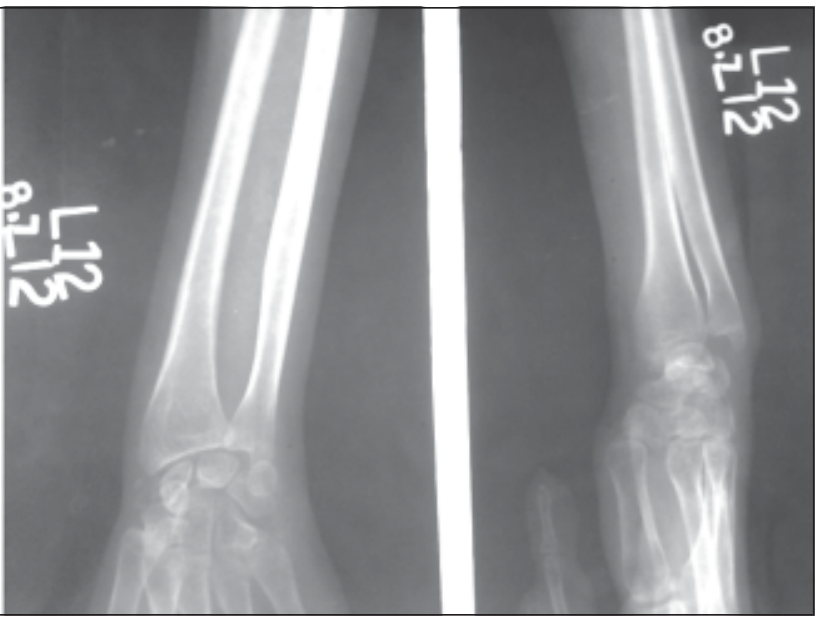

Fig-1(b)

elbow and left wrist joint showed [fig-1(a) \& (b)] radioulnar sublaxation in elbow joint and mild soft tissue swelling around wrist joint. MRI of brain showed-focal area of signal intensity with surrounding hyperintensity noted in the right frontotemporo-parietal region along with exvaculodilatation of right lateral ventricle, hemiatrophy of right cerebral hemisphere,right cranial fossa smaller in size with slightly thickened skull bones and right lateral ventricular dilation [2(a),(b) \& (c)]. Mucosal thickening in ethmoidal \& maxillary sinuses suggesting sinusitis. So encephalomalacic changes in right fronto-temporo-parietal region \& other findings are in favors of Dyke-Davidoff-Masson Syndrome.

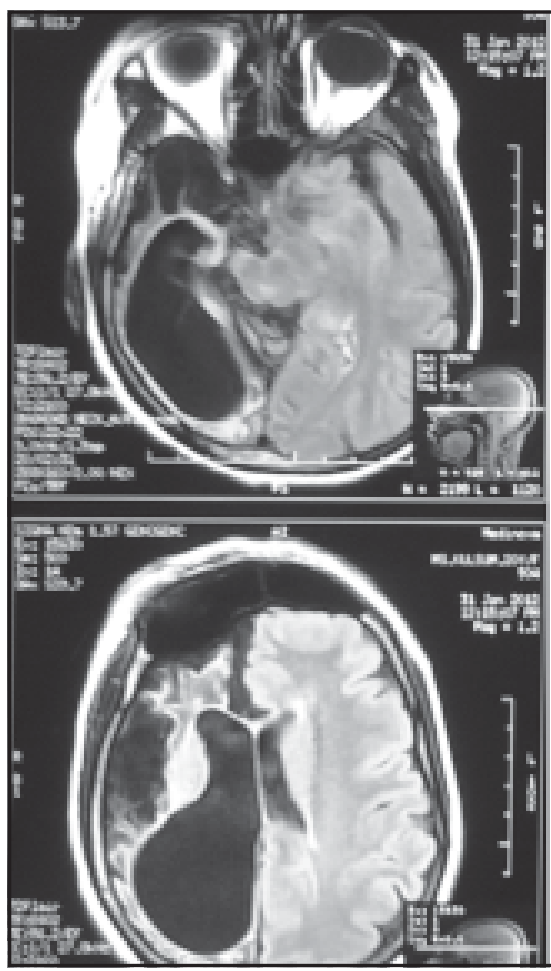

Fig-2(a)

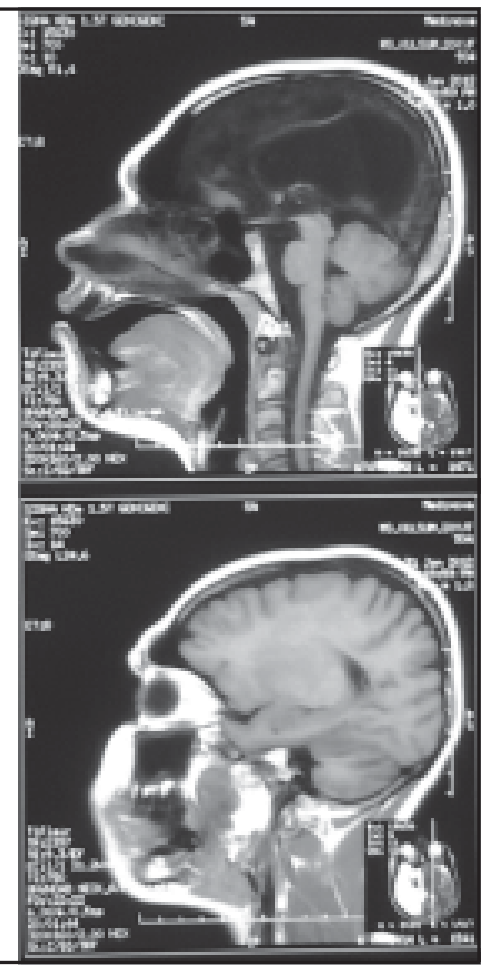

Fig-2(b) 

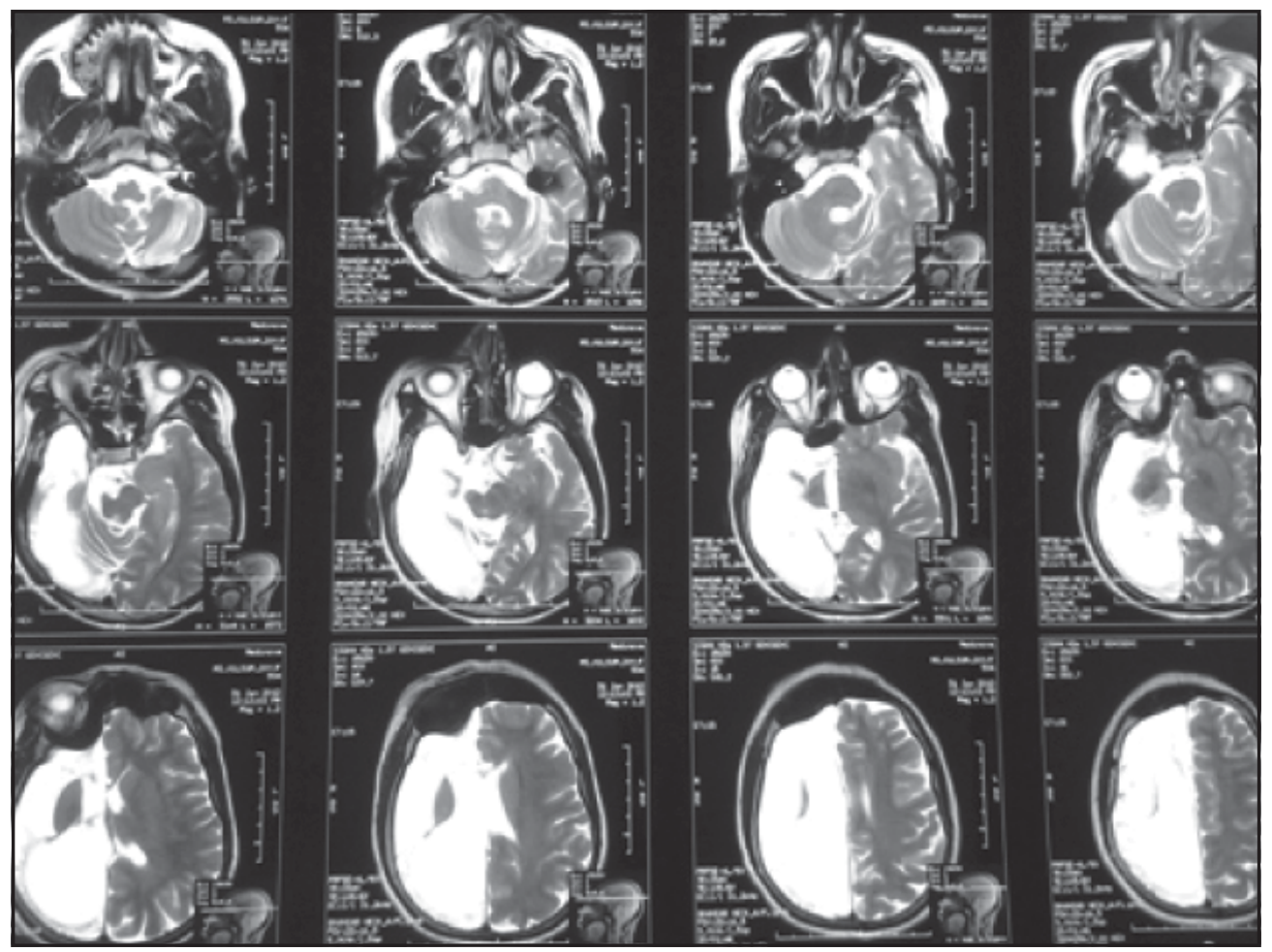

Fig-2(c)

\section{Discussion}

Cortical hemiatrophy, hemiparesis, and seizures are the typical features of DDMS ${ }^{(1)}$. The patient may develop seizure at first and then hemiparesis which was seen in this case or vice versa. Mental retardation appear years after the onset of hemiparesis ${ }^{2}$. As Jules Cotard firstly recorded that unilateral cerebral atrophy in infancy does not necessarily lead to aphasia ${ }^{9}$, DDMS patient not necessarily be aphasic. Radiological features of DDMS are unilateral loss of cerebral volume and associated compensatory bone alterations in the calvarium, like thickening, hyperpneumatization of the paranasal sinuses and mastoid cells and elevation of the petrous ridge and greater wing of the sphenoid bone ${ }^{(10)}$. This case presented with most of the typical features of DDMS: cerebral hemiatrophy, seizures, contralateral hemiparesis, and mental retardation. Moreover compensatory cerebral hypertrophy was seen at contralateral hemisphere. The etiological factor in this patient was infection in the childhood that led the febrile seizure and recurrent seizures which inhibited the development of affected cortex. Garg et al. had also reported a similar etiological relation of cerebral hemiatrophy with febrile seizures ${ }^{(11)}$. The prominent sulci and encephalomalacia in the atrophic hemisphere reflect a late onset of brain insults due to abnormal neuronal and glial proliferation or apoptosis during cortical development which were the consequence of intracranial infection in this case. On the other hand, if the brain insults occurs during embroyogenesis, when the formation of gyri and sulci is incomplete, no prominent sulci will be present ${ }^{(10)}$. Typical skull changes develop when insult to the brain occurs during the first 18 months to 2 years of life. In cerebral atrophy, whether unilateral or bilateral, focal or diffuse, the common factor is loss of brain tissue, although the nature and extent of the underlying pathologic processes vary widely. Adaptation to unilateral decrease of brain substance may consist calvarial thickening affecting particularly the diploic space with loss of convolutional markings of the inner table of the skull ${ }^{1,2}$, overdevelopment of the frontal and ethmoid sinuses and of the mastoid air cells, elevation of the petrous ridge, dilatation of one lateral ventricle and displacement of the midline structures toward the atrophic side and widened subarachnoid space on the affected side.

Conditions that are associated with cerebral hemiatrophy such as Rasmussen encephalitis, Sturge-Weber syndrome, some brain tumors, Silver's syndrome, linear nevus sebaceous syndrome and progressive multifocal leucoencephalopathy should be differentiated. Cerebral hemiatrophy without seizure most likely cause due to cerebrovascular disease $^{12}$. Medically intractable patients are the 
candidates for the surgical treatment in an attempt to achieve better seizure control. Functional imaging like MRI can visualize alterations in cerebral perfusion or metabolism that provides important information regarding the localization of eloquent cortex adjacent to the lesions or planned resection line ${ }^{(13)}$. The treatment of DDMS with multiple antiepileptics is the best option. If the seizures are refractory, hemi-spherectomy is the best treatment option.

\section{Conclusion}

In summary, a patient with DDMS is rarely reported in the literature and various etiological factors play role in this syndrome. We believe that our case is worthy of particular attention because of the rarity of the disease.

\section{References}

1. Dyke CG, Davidoff LM, Masson CB: Cerebral hemiatrophy with homolateral hypertrophy of the skull and sinuses. Surg Gynecol Obstet 57:588-600, 1933.

2. Zilkha A: CT of cerebral hemiatrophy. AJR Am J Roentgenol 135:259-262, 1980.

3. Unal O, Tombul T, Cirak B, Anlar O, Incesu L, Kayan M: Left hemisphere and male sex dominance of cerebral hemiatrophy (Dyke-Davidoff-Masson Syndrome). Clin Imaging 28:163-165, 2004.

4. Afifi AK, Godersky JC, Menezes A, Smoker WR, Bell WE, Jacoby CG: Cerebral hemiatrophy, hypoplasia of internal carotid artery and intracranial aneurysm.
A rare association occurring in an infant. Arch Neurol 44:232-235, 1987.

5. Ono K, Komai K, Ikeda T: Dyke-Davidoff-Masson syndrome manifested by seizure in late childhood: A case report. J Clin Neurosci 10:367-371, 2003.

6. Stred SE, Byrum CJ, Bove EL, Oliphant M: Coarctation of the midaortic arch presenting with monoparesis. Ann Thorac Surg 42:210-212, 1986.

7. Tasdemir HA, Incesu L, Yazicioglu AK, Belet U, Gungor L: Dyke-Davidoff-Masson syndrome. Clin Imaging 26:13-17, 2002.

8. Sener RN, Jinkins JR: MR of craniocerebral hemiatrophy. Clin Imaging 16:93-97, 1992.

9. Pearn J, Gardner-Thrope C: Jules Cotard (18401889): His life and the unique syndrome which bears his name.Neurology 58:1400-1403, 2002.

10. Aguiar PH, Liu CW, Leitao H, Issa F, Lepski G, Figueiredo EG, Gomes-Pinto F, Marino Junior R: MR and CT imaging in the Dyke-Davidoff-Masson syndrome. Report of three cases and contribution to pathogenesis and differential diagnosis. Arq Neuropsiquiatr 56:803-807, 1998.

11. Garg RK, Karak B: Cerebral Hemiatrophy: A possible etiological relation with febrile seizures. Indian Pediatr 35:7 9-81, 1998.

12. Nieman EA, Fullerton PM: Electroencephalographic findings in unilateral cerebral atrophy. Neurology 13:213-218, 1963.

13. Cosgrove GR, Andrew JC: Identification of candidates for epilepsy surgery. In: Winn HR, ed. Youmans Neurological Surgery. Philadelphia: WB Saunders, 2004: 2525-2530. 